\title{
Frequency Control in Dispersed Power System Using Partially Decentralized Combined Fuzzy-PID (PD-CFPID) Regulator
}

\author{
Pabitra Mohan Dash, Sangram Keshori Mohapatra and Asini Kumar Baliarsingh \\ Department of Electrical Engineering, BEC, Bhubaneswar, Odisha, India \\ Department of Electrical Engineering, GCE, Keonjhar, Odisha, India \\ Department of Electrical Engineering, GCE, Kalahandi, Odisha, India \\ e-mail: pmdash.bbsr@gmail.com, sangram.muna.76@gmail.com*, asinikumar333@gmail.com
}

\begin{abstract}
The uncertain nature of solar, wind sources and load demand in presence of electric vehicles makes modern power system more complicated and introduces the frequency oscillations. It is highly needed to establish power balance among generation and demand by designing an appropriate controller for frequency regulation. Henceforth, this research presents a maiden application of sine cosine adapted improved whale optimization algorithm (SCiWOA) for a Partially Decentralized Combined Fuzzy PID(PD-CFPID) controller to control the frequency of dispersed power system (DPS) with electric vehicle. The proposed PD-CFPID controller is suggested for frequency control of dispersed power system (DPS) with electric vehicle. To optimized the controller parameters, a sine cosine adapted improved whale optimization algorithm (SCiWOA) has been employed. In the proposed SCiWOA technique, sine and cosine functions are incorporated in the original Whale Optimization Algorithm (WOA) for control parameter selection. Furthermore, scaling factors are engaged in original WOA technique to adjust the travel of search agents in the search procedure. The performance of SCiWOA is analysed by applying on benchmark functions and equated with other similar methods. Next a practical application of DPS frequency control is performed by designing a PDCFPID controller using proposed SCiWOA technique. It is demonstrated that SCiWOA technique out performs WOA technique in controller design problem. It is noticed that SCiWOA based PD-CFPID controller is more effective in controlling the frequency relative to similar structured Centralized Fuzzy PID (CFPID) as well as PID controller. Lastly, the outcome of PDCFPID controller is equated with CFPID and PID controller under different serious uncertain scenarios to illustrate the advantage of proposed frequency control approach
\end{abstract}

Keywords: Sine-Cosine Adapted Improved WOA (SCiWOA); Partially Decentralized Combined Fuzzy PID (PD-CFPID); Whale Optimization Algorithm (WOA); Hybrid Power System; Electric Vehicle

\section{Nomenclature: \\ $\mathrm{f}=$ system frequency deviation \\ $\mathrm{KPV}=$ gain of $\mathrm{PV}$ System \\ $\mathrm{GPV}(\mathrm{S})=$ transfer function of solar photovoltaic $\mathrm{TPV}=$ time constant of solar photovoltaic \\ $\mathrm{PPV}=$ output power of solar photovoltaic system \\ PWTG $=$ power output of wind generator \\ GWTG(S)=transfer function of wind generator \\ $\mathrm{KWTG}=$ gain of wind generator \\ TWTG =time constant of wind generator \\ $\mathrm{GAE}(\mathrm{S})=$ transfer function of aqua electrolysers}

PAE $=$ power output of aqua electrolyser

$\mathrm{KAE}=$ gain of the aqua electrolyser

$\mathrm{TAE}=$ time constant of the aqua electrolyser

$\mathrm{TFC}=$ time constant of fuel cell

$\mathrm{GFC}(\mathrm{S})=$ transfer function of fuel-cell

generators
$\mathrm{PFC}=$ output power of fuel-cell generators

$\mathrm{KFC}=$ gain of fuel cell

GFESS(S) = transfer function of flywheel energy storage system

KFESS = gain of flywheel energy storage system TFESS = time constant of flywheel energy storage system

PFESS $=$ power of flywheel energy storage system

PDEG $=$ output power of diesel generators

GDEG(S) = transfer function of diesel generator

$\mathrm{KDEG}=$ gain of diesel generator

TDEG $=$ time constant of diesel generator

PBESS= power of battery energy storage system GBESS(S) = transfer function of battery energy storage system

$\mathrm{KBESS}=$ gain of battery energy storage system

Received: March $3^{\text {th }}, 2021$. Accepted: September $29^{\text {th }}, 2021$

DOI: $10.15676 /$ ijeei.2021.13.3.14 
TBESS = time constant of battery energy storage system

$\mathrm{PS}=$ total power generation to the system

$\mathrm{PL}=$ Average power absorbed by loads

$\mathrm{M}=$ inertia constant of the hybrid power system

$\mathrm{D}=$ damping constant of the hybrid power system

$\mathrm{DPS}=$ frequency of dispersed power system
$\mathrm{PID}=$ Proportional Integral Controller PD-CFPID $=$ Partially Decentralized Combined Fuzzy PID CFPID $=$ Centralized Fuzzy PID WOA $=$ Whale Optimization Algorithm SCiWOA $=$ sine cosine adapted improved whale optimization algorithm

\section{Introduction}

The increasing of addition of unpredictable renewable sources, such as solar \&wind power, electrical vehicles, distributed energy sources and random load variations, modern power systems are susceptible to frequency fluctuations. In such a situation, an appropriate controller is needed for frequency regulation. Distributed control approach has multiple distributed controllers for each controllable energy source located within the Distributed Power System (DPS). However, distributed control approach requires one to one communication between each controllable source. Complete control requirements such as matching collective load \&generation or optimum generation combination is not usually achievable with distributed control scheme. Hence, if system optimization is the objective, a centralized control scheme is generally favored. In centralized control scheme, all control requirements are handled by a central computer. However centralized approaches frequently suffer if there is a single failure and decentralized schemes are usually associated with difficult practical implementations and costly communication requirements. Considering the shortcomings of both centralized and decentralized control schemes, this paper proposes to use a partially decentralized controller for frequency regulation of DPS. The proposed partially decentralized control scheme which compared with the decentralized control can take the coupling information into account, thus enhancing the system performance but not make the design process too complicated. Design of controller is a perplexing work. Therefore, a number of favorable approaches have been put forward for consideration by researchers in this regard. WOA is a lately suggested method which is based on pursues and captures skill of Humpback whale [1]. Though WOA is an efficient method, it has a penchant to be struck in local bests with inferior convergence characteristic. In the literature survey it is observed that, several changes have been made to enhance the execution and to improve the performance of WOA technique. Authors have proposed to use Levy flight trajectory [2], inertia weights [3], Simulated Annealing (SA) [4], fixed correction factors [5, 6] etc for achieving an advance the performance of WOA. However, the No Free Lunch (NFL) scheme highlights that there is no technique which can fight fit to every problem. In the present work, an improved WOA, Sine-Cosine-Adapted-Improved-Whale-Optimization-Algorithm (SCiWOA) is suggested, where scaling factors are used to change the step size in position updating as well as to determine the control parameter ' $c$ ' of the WOA in the optimization process. The algorithm is verified on benchmark functions, compared with other intelligent methods and then employed for designing a partially decentralized controller to control the frequency of a dispersed generation system containing renewable energy sources like (solar, wind, photovoltaic etc), energy storage devices like (battery, flywheel) and plug-in electric vehicles. Renewable energy sources are indeterminate in nature and the power demand causes fluctuation of frequency. Therefore, frequency control is essential through a suitable controller to maintain power balance in the system between generations and load. Keeping in view to the above facts, different approaches have been proposed by researchers to improve the performances in load flow control. From the literature survey it is observed that the performance of conventional controllers like PI, PID etc are found to be poor with respect to system nonlinearities and constraints. For enhancing the performances, Fuzzy Logic controllers (FLC) have been considered by a number of researchers in the Load Flow Control scheme, which is capable to deal with nonlinearities and constraints by using input/output scaling factors and tunable controller parameters [8]. Action combination of FLC and PID controllers are suggested in literatures [9-11] for getting necessary regulation. 
Partially Decentralized Combined Fuzzy PID (PD-PID) controller is suggested in this paper to deal with the effects of scaling factors on the control operation. With its gain updating factor, the input signal is accepted by the proposed controller directly which in turn the output scaling factor of FPID is modified. Its parameters are optimized by SCiWOA technique. The main aim of the proposed work includes: -

1. To suggest SCiWOA and to show its advantages over other acknowledged optimization techniques such as Cosine Adapted Modified WOA (Cam WOA), Water Cycle Algorithm (WCA), Moth Flame Optimization (MFO) Algorithm, Artificial Bee Colony (ABC), Particle Swarm Optimisation (PSO), Gravitational Search Algorithm (GSA), Hybrid PSO and GSA (PSOGSA), Genetic Algorithm (GA), Dragonfly Algorithm (DA) [12] using benchmark functions.

2. To employ Partially Decentralized Combined Fuzzy PID (PD-PID) controller in a view to regulate Dispersed Power Generation to demonstrate the supremacy of PD-CFPID.

3. To validate the suitability and effectiveness of SCiWOA based PD-PID controller under various uncertainties and contingencies such as increase in load demand, less generation due to insufficient implementation of renewable energy sources and communication delay.

\section{Sine-Cosine Adapted Improved WOA (SCiWOA)}

\section{A. Overview of SCiWOA}

Whale optimization is an intelligent technique inspired by social behavior of humpback whales for probing of food or prey through bubble net hunting strategy on water surface. Whale encircles the prey by making bubbles in a circular path and hunts by swimming about it in shrinking loop. The encircling technique and bubbly attack represent the exploration and exploitation in the Meta heuristic optimization technique. The location of the best pattern in the area where the encircling prey is searched initially by the whale is unknown. At this stage the whale considers that the marked prey is the best solution. This implies that the solution is approaching the optimal value. Then the best searching agent is selected among the whales and accordingly position updating is done by rest of the whales simultaneously guided by the best whale. The update was best made as per the location of the whale during exploitation phase that has been performed randomly in the discovery phase. In the exploitation phase of WOA which is governed by bubble-net attacking technique. Shrinking encircling method and spiral updating position are the two approaches to approaches used for this. These methods are explained by Eqs. (1) - (3).

$$
\vec{F}=|\vec{E} \cdot \vec{Z} *(t)-\vec{Z}(t)|
$$

Eq-1 guarantees that any whale will revise its location in the proximate of current best whale. $\vec{E}$ represents the distance among $i^{t h}$ and the best whale obtained up to the present time. $\vec{Z}^{*}(t)$ Indicates the best solution till now, $\vec{Z}(t)$ is the position vector and ' $t$ ' represents the current iteration.

$$
\vec{Z}(t+1)=\vec{Z} *(t)-\vec{C} \cdot \vec{F}
$$

The position updating of agent is performed according to Eq. (2) to reach at best solution.

$$
\vec{Z}(t+1)=\vec{F}^{\prime} \cdot e^{k l} \cdot \cos (2 \pi l)+\vec{Z}^{*}(t)
$$

Where, in Eq.(3), $\vec{F}^{\prime}=|\vec{Z} *(t)-\vec{Z}(t)|$ represents the distance between $t^{\text {th }}$ whales to finest found prey up to the present time, ' $k$ ' is the contour of logarithmic spiral and ' $l$ ' represents a number in the interval $[-1,1]$.

$\vec{C}$ and $\vec{E}$ are vectors which control the area of finding the whale in the proximate of prey and are estimated from Eq. (4) and (5) as: 


$$
\begin{aligned}
& \vec{C}=2 \vec{c} \vec{r}-\vec{c} \\
& \vec{E}=2 \vec{r}
\end{aligned}
$$

Where, $\vec{r}$ is an arbitrary number between $1 \& 0$ $\rightarrow$

$c$ represents distance control parameter. Its value decreases from 2 to 0 linearly in optimization process. The shrinking characteristic is guaranteed as $\vec{c}$ reduces.

Altercation among exploitation and exploration stage follows with linearly sinking ' $\vec{c}$ ' as Eq. (6).

$$
\vec{c}=2-t \frac{2}{I T E R_{M A X}}
$$

Here, $t$ and $I T E R_{M A X}$ represents current and maximum iterations respectively.

A sine function is used in control parameter ' $\vec{c}$ 'in the proposed SCiWOA process as shown in Eq. (7).

$$
\vec{c}= \begin{cases}1-\sin \left(\frac{\pi}{2}\left(\frac{t}{I T E R_{M A X}}\right)\right) & \text { if } R N D<0.5 \\ 1-\cos \left(\frac{\pi}{2}\left(\frac{t}{I T E R_{M A X}}\right)\right) & \text { if } R N D \geq 0.5\end{cases}
$$

Here, $R N D$ is an arbitrary value that can be taken the interval $[0,1]$.

Use of sine and cosine function for $\vec{c}$ 'give rise to a fluctuating exploration and exploitation in the iteration process. Sine and Cosine functions are cyclic. Their implementation allows an agent to be repositioned in the region of another agent. Appropriate exploitation and exploration of search area can be warranted by this method.

In the WOA technique, the target of a whale is the best whale when other whales try to update their positions near to it. In the early stages, the finest likely search agent is unknown and modification of this method uses large steps initially. Such modifications may result far off the best in moving whales. Consequently, in the exploration stage introduction of scaling factors $(S F)$ in SCiWOA controls the progress of search agents throughout the search process given by the following equations.

$$
\begin{aligned}
& \vec{F}=\left|\vec{E} \cdot \overrightarrow{Z^{*}}(t)-\vec{Z}(t)\right| / S F \\
& \vec{Z}(t+1)=\left(\overrightarrow{Z^{*}}(t)-\vec{C} \cdot \vec{F}\right) / S F \\
& \vec{Z}(t+1)=\left(\vec{F}^{\prime} \cdot e^{k l} \cdot \cos (2 \pi l)+\vec{Z}^{*}(t)\right) / S F
\end{aligned}
$$

In WOA technique, reorganization of position of the search agent is done in exploration stage with reference to a randomly chosen search agent who guides the arbitrary movement of whales in the preliminary stage. In SCiWOA, the location is altered by scaling factors using equations. (11) and (12):

$$
\begin{aligned}
& \vec{F}=\left(\vec{E} \cdot \vec{Z}_{\text {rand }}(t)-\vec{Z}\right) / S F \\
& Z(\vec{t}+1)=\left(\vec{Z}_{\text {rand }}-\vec{C} \cdot \vec{F}\right) / S F
\end{aligned}
$$


The scaling factor is varied as given below.

$$
S F= \begin{cases}2-\frac{t}{I T E R_{M A X}} & \text { if } R N D 1<0.5 \\ 1 /\left(2-\frac{t}{I T E R_{M A X}}\right) & \text { if } R N D 1 \geq 0.5\end{cases}
$$

At the beginning stage of search process, motion of whales is modified by inclusion of scaling factors in both exploitation and exploration phases which in turn refines the search capability of the process. Gradually better solutions are obtained during the later stages and whales move towards them at normal speed.

\section{Performance Study of SCiWOA Algorithm}

Table 1. Unimodal benchmark function

\begin{tabular}{lcc}
\hline \multicolumn{1}{c}{ Functions } & Range & $f_{\text {min }}$ \\
\hline$p_{1}(y)=\sum_{i=1}^{n} y_{i}^{2}$ & {$[-100,100]^{10}$} & 0 \\
$p_{2}(y)=\sum_{i=1}^{n}\left|y_{i}\right|+\prod_{i=1}^{n} y_{i}$ & {$[-10,10]^{10}$} & 0 \\
$p_{3}(y)=\sum_{i=1}^{n}\left(\sum_{j-1}^{i} y_{j}\right)^{2}$ & {$[-100,100]^{10}$} & 0 \\
$p_{4}(y)=\max _{i}\left\{\left|y_{i}\right|, 1 \leq i \leq n\right\}$ & {$[-100,100]^{10}$} & 0 \\
$p_{5}(y)=\sum_{i=1}^{n-1}\left[100\left(y_{i+1}-y_{i}^{2}\right)^{2}+\left(y_{i}-1\right)^{2}\right]$ & {$[-30,30]^{10}$} & 0 \\
$p_{6}(y)=\sum_{i=1}^{n}\left(\left[y_{i}+0.5\right]\right)^{2}$ & {$[-100,100]^{10}$} & 0 \\
$p_{7}(y)=\sum_{i=1}^{n} i y_{i}^{4}+$ random $[0,1)$ & {$[-1.28,1.28]^{10}$} & 0 \\
\hline
\end{tabular}

Table 2. Multimodal benchmark function

\begin{tabular}{ccc}
\hline \multicolumn{1}{c}{ Function } & Range & $f_{\min }$ \\
\hline$p_{8}(y)=\sum_{\mathrm{i}=1}^{\mathrm{n}}-\mathrm{y}_{\mathrm{i}} \sin \left(\sqrt{\left|\mathrm{y}_{\mathrm{i}}\right|}\right)$ & {$[-500,500]^{10}$} & -2094.9145 \\
$p_{9}(y)=\sum_{\mathrm{i}=1}^{\mathrm{n}}\left[\mathrm{y}_{\mathrm{i}}^{2}-10 \cos \left(2 \pi \mathrm{y}_{\mathrm{i}}\right)+10\right]$ & {$[-5.12,5.12]^{10}$} & 0 \\
$p_{10}(y)=-20 \exp \left(-0.2 \sqrt{\frac{1}{n} \sum_{i=1}^{n} y_{i}^{2}}\right)-\exp \left(\frac{1}{n} \sum_{i=1}^{n} \cos \left(2 \pi y_{i}\right)\right)$ & {$[-32,32]^{10}$} & 0 \\
$+20+e$ & {$[-600,600]^{10}$} & 0 \\
$p_{11}(y)=\frac{1}{4000} \sum_{\mathrm{i}=1}^{\mathrm{n}} \mathrm{y}_{\mathrm{i}}^{2}-\prod_{\mathrm{j}=1}^{\mathrm{n}} \cos \left(\frac{\mathrm{y}_{\mathrm{i}}}{\sqrt{\mathrm{i}}}\right)+1$ & {$[-50,50]^{10}$} & 0 \\
$p_{12}(y)=\frac{\pi}{\mathrm{n}}\left\{10 \sin \left(\pi \mathrm{x}_{\mathrm{i}}\right)+\sum_{\mathrm{i}=1}^{\mathrm{n}-1}\left(\mathrm{y}_{\mathrm{i}}^{-} 1\right)^{2}\left[1+10 \sin ^{2}\left(\pi \mathrm{x}_{\mathrm{i}+1}\right)\right]\right\}$ & & \\
$+\left(\mathrm{x}_{\mathrm{n}}-1\right)^{2}+\sum_{\mathrm{i}=1}^{\mathrm{n}} \mathrm{u}\left(\mathrm{y}_{\mathrm{i}}, 10,100,4\right)$ & \\
$x_{i}=1+\frac{y_{i}+1}{4}$ & & \\
$k\left(y_{i}-a\right)^{m} y_{i}>a$ & & \\
$0-a<y_{i}<a$ & \\
$k\left(-y_{i}-a\right)^{m} y_{i}<a$ & & \\
$u\left(y_{i}, a, k . m\right)=$ &
\end{tabular}




$$
\begin{aligned}
& p_{13}(y)=0.1\left\{\sin ^{2}\left(3 \pi y_{i}\right)\right. \\
& +\sum_{i=1}^{n}\left(y_{i}-1\right)^{2}\left[1+\sin ^{2}\left(3 \pi y_{i}+1\right)\right] \\
& \left.+\left(y_{n}-1\right)^{2}\left[1+\sin ^{2}\left(2 \pi y_{n}\right)\right]\right\}+\sum_{i=1}^{n} u\left(y_{i}, 5,100.4\right)
\end{aligned}
$$

\begin{tabular}{|c|c|c|c|c|c|c|c|c|}
\hline \multirow[b]{2}{*}{ Function } & \multicolumn{2}{|c|}{ SCiWOA } & \multicolumn{2}{|c|}{ WOA } & \multicolumn{2}{|c|}{ WCMFO } & \multicolumn{2}{|c|}{$\mathrm{ABC}$} \\
\hline & Avg. value & $\begin{array}{l}\text { Std. } \\
\text { Dev. }\end{array}$ & $\begin{array}{l}\text { Avg. } \\
\text { value }\end{array}$ & $\begin{array}{l}\text { Std. } \\
\text { Dev. }\end{array}$ & $\begin{array}{l}\text { Avg. } \\
\text { value }\end{array}$ & $\begin{array}{l}\text { Std. } \\
\text { Dev. }\end{array}$ & $\begin{array}{l}\text { Avg. } \\
\text { value }\end{array}$ & $\begin{array}{l}\text { Std. } \\
\text { Dev. }\end{array}$ \\
\hline$p_{1}(y)$ & 0 & 0 & $9.81 \mathrm{E}-200$ & 0 & $1.10 \mathrm{E}-95$ & $6.05 \mathrm{E}-95$ & $1.93 \mathrm{E}-2$ & $1.46 \mathrm{E}-2$ \\
\hline$p_{2}(y)$ & $2.54 \mathrm{E}-273$ & 0 & $7.43 \mathrm{E}-117$ & $4.11 \mathrm{E}-116$ & $3.51 \mathrm{E}-33$ & $1.33 \mathrm{E}-32$ & $3.42 \mathrm{E}-2$ & $1.3 \mathrm{E}-2$ \\
\hline$p_{3}(y)$ & $2.45 \mathrm{E}-268$ & 0 & 0.0288 & 0.0693 & $1.58 \mathrm{E}-32$ & $8.83 \mathrm{E}-32$ & 848.34 & 227.45 \\
\hline$p_{4}(y)$ & $9.12 \mathrm{E}-199$ & 0 & 0.0039 & 0.0175 & $3.28 \mathrm{E}-24$ & $1.30 \mathrm{E}-23$ & 7.939 & 1.938 \\
\hline$p_{5}(y)$ & 8.644 & 0.4157 & 9.3285 & 25.0602 & 2.4064 & 3.333 & 44.513 & 15.196 \\
\hline$p_{6}(y)$ & 0.1866 & 0.0976 & 7.63E-07 & $5.22 \mathrm{E}-07$ & $7.01 \mathrm{E}-29$ & $3.27 \mathrm{E}-28$ & $1.13 \mathrm{E}-2$ & $7.3 \mathrm{E}-3$ \\
\hline$p_{7}(y)$ & $3.68 \mathrm{E}-05$ & $3.15 \mathrm{E}-05$ & $4.22 \mathrm{E}-04$ & $5.56 \mathrm{E}-04$ & 0.4792 & 0.341 & $3.93 \mathrm{E}-2$ & $1.09 \mathrm{E}-2$ \\
\hline \multirow[b]{2}{*}{ Function } & \multicolumn{2}{|c|}{ PSOGSA } & \multicolumn{2}{|c|}{ CamWOA } & \multicolumn{2}{|c|}{ GSA } & \multicolumn{2}{|c|}{ MFO } \\
\hline & Avg. value & $\begin{array}{l}\text { Std. } \\
\text { Dev. }\end{array}$ & Avg. value & $\begin{array}{l}\text { Std. } \\
\text { Dev. }\end{array}$ & $\begin{array}{l}\text { Avg. } \\
\text { value }\end{array}$ & $\begin{array}{l}\text { Std. } \\
\text { Dev. }\end{array}$ & $\begin{array}{l}\text { Avg. } \\
\text { value }\end{array}$ & $\begin{array}{l}\text { Std. } \\
\text { Dev. }\end{array}$ \\
\hline$p_{1}(y)$ & $1.24 \mathrm{E}-20$ & $3 \mathrm{E}-21$ & 0 & 0 & $1.02 \mathrm{E}-18$ & $3.3 \mathrm{E}-19$ & $1.65 \mathrm{E}-31$ & $4.91 \mathrm{E}-31$ \\
\hline$p_{2}(y)$ & $2.58 \mathrm{E}-10$ & $4.57 \mathrm{E}-11$ & $2.1 \mathrm{E}-317$ & 0 & $2.33 \mathrm{E}-09$ & $4.39 \mathrm{E}-10$ & $2.69 \mathrm{E}-19$ & $6.22 \mathrm{E}-19$ \\
\hline$p_{3}(y)$ & $2.48 \mathrm{E}-20$ & $9.34 \mathrm{E}-21$ & 0 & 0 & $1.00 \mathrm{E}-05$ & $5.50 \mathrm{E}-05$ & $2.05 \mathrm{E}-11$ & $4.21 \mathrm{E}-11$ \\
\hline$p_{4}(y)$ & $6.35 \mathrm{E}-11$ & $1.26 \mathrm{E}-11$ & $4.5 \mathrm{E}-306$ & 0 & $4.76 \mathrm{E}-10$ & $8.44 \mathrm{E}-11$ & $5.79 \mathrm{E}-06$ & $3.17 \mathrm{E}-05$ \\
\hline$p_{5}(y)$ & 1.1607 & 2.0941 & 6.8177 & 0.602 & 5.423 & 0.1238 & 133.11 & 555.57 \\
\hline$p_{6}(y)$ & $1.38 \mathrm{E}-20$ & $3.37 \mathrm{E}-21$ & 0.001415 & 0.000982 & $6.40 \mathrm{E}-19$ & $2.30 \mathrm{E}-19$ & $4.78 \mathrm{E}-32$ & $1.27 \mathrm{E}-31$ \\
\hline$p_{7}(y)$ & $2.3 \mathrm{E}-3$ & $1.2 \mathrm{E}-3$ & $1.77 \mathrm{E}-05$ & $1.38 \mathrm{E}-05$ & $1.86 \mathrm{E}-3$ & $6.7 \mathrm{E}-4$ & $1.2 \mathrm{E}-3$ & $7.2 \mathrm{E}-4$ \\
\hline \multirow[b]{2}{*}{ Function } & \multicolumn{2}{|c|}{ GA } & \multicolumn{2}{|c|}{ PSO } & \multicolumn{2}{|c|}{$\mathrm{DA}$} & \multicolumn{2}{|c|}{ WCA } \\
\hline & Avg. value & $\begin{array}{l}\text { Std. } \\
\text { Dev. }\end{array}$ & Avg. value & $\begin{array}{l}\text { Std. } \\
\text { Dev. }\end{array}$ & $\begin{array}{l}\text { Avg. } \\
\text { value }\end{array}$ & $\begin{array}{l}\text { Std. } \\
\text { Dev. }\end{array}$ & $\begin{array}{l}\text { Avg. } \\
\text { value }\end{array}$ & $\begin{array}{l}\text { Std } \\
\text { Dev. }\end{array}$ \\
\hline$p_{1}(y)$ & $8 \mathrm{E}-4$ & $8.7 \mathrm{E}-4$ & $7.38 \mathrm{E}-54$ & $2.17 \mathrm{E}-53$ & $5.303 \mathrm{E}-1$ & 1.3180 & $3.1 \mathrm{E}-14$ & $5.8 \mathrm{E}-14$ \\
\hline$p_{2}(y)$ & $3 \mathrm{E}-3$ & $1.8 \mathrm{E}-3$ & $5.68 \mathrm{E}-31$ & $1.38 \mathrm{E}-30$ & 2.392 & 3.912 & $2.11 \mathrm{E}-07$ & $3.96 \mathrm{E}-07$ \\
\hline$p_{3}(y)$ & 13.213 & 8.042 & $3.15 \mathrm{E}-18$ & $9.67 \mathrm{E}-18$ & 215.45 & 935.17 & $3.56 \mathrm{E}-12$ & $9.56 \mathrm{E}-12$ \\
\hline$p_{4}(y)$ & 0.209 & $5.8 \mathrm{E}-2$ & $4.3 \mathrm{E}-16$ & $9.76 \mathrm{E}-16$ & 1.153 & 2.702 & $1.08 \mathrm{E}-11$ & $5.73 \mathrm{E}-11$ \\
\hline$p_{5}(y)$ & 16.913 & 22.375 & 3.311 & 1.647 & 6784.5 & 21974.5 & 1.252 & 1.831 \\
\hline$p_{6}(y)$ & $7.5 \mathrm{E}-4$ & $7.2 \mathrm{E}-4$ & 0 & 0 & 2.2023 & 5.528 & $4.6 \mathrm{E}-18$ & $2.26 \mathrm{E}-17$ \\
\hline$p_{7}(y)$ & $8.1 \mathrm{E}-4$ & $5.5 \mathrm{E}-4$ & $1.4 \mathrm{E}-3$ & $7 \mathrm{E}-4$ & $6.9 \mathrm{E}-3$ & $7.6 \mathrm{E}-3$ & 0.5155 & 0.2552 \\
\hline
\end{tabular}

Table 3. Statistical of unimodal functions

SCiWOA is suggested and verified on some bench mark functions in the present work [13, 14, and 17] which are shown in Tables 1 and 2. To validate the effectiveness of the suggested SiWOA process it is equated with WOA, newly projected WCMFO [12] and ABC [15], GA [16], CamWOA[17], PSO[18], GSA [19], PSOGSA[20], WCA[21], MFO[22] and DA [23] as described in the literature $[12,17] .100000$ functions are taken in all methods towards impartial comparison and 100 search agents with 1000 iterations has been taken for evaluation in the proposed algorithm (SCiWOA). Each technique is executed for 30 times. Parameters of the algorithm in connection to all methods are taken for reference [12,17]. Different values of scaling factor $(S F)$ are allocated and verified in bench mark functions for proper selection. The mean 
and standard deviation of the objective function found from 30 runs are collected and 17 functions out of 23 [ i.e. $p_{1}(y), p_{3}(y), p_{4}(y), p_{7}(y), p_{9}(y), p_{10}(y), p_{11}(y), p_{12}(y), p_{13}(y), p_{14}(y)$, $\left.p_{15}(y), p_{16}(y), p_{17}(y), p_{18}(y), p_{19}(y), p_{21}(y), p_{22}(y)\right]$ are found as best results in comparison to other values when $S F$ are varied from 2 to 1 .

\section{A. Analysis of exploitation capacity $\left(p_{1}(\mathrm{y})-p_{7}(\mathrm{y})\right)$}

Table 4. Statistical of multimodal functions

\begin{tabular}{|c|c|c|c|c|c|c|c|c|}
\hline \multirow[t]{2}{*}{ Function } & \multicolumn{2}{|c|}{ SCiWOA } & \multicolumn{2}{|c|}{$\overline{\text { WOA }}$} & \multicolumn{2}{|c|}{ WCMFO } & \multicolumn{2}{|c|}{$\mathrm{ABC}$} \\
\hline & Avg. value & $\begin{array}{l}\text { Std. } \\
\text { Dev. }\end{array}$ & $\begin{array}{l}\text { Aveg. } \\
\text { value }\end{array}$ & $\begin{array}{c}\text { Std. } \\
\text { Dev. }\end{array}$ & $\begin{array}{l}\text { Avg. } \\
\text { value }\end{array}$ & $\begin{array}{l}\text { Std. } \\
\text { Dev. }\end{array}$ & $\begin{array}{l}\text { Avg. } \\
\text { value }\end{array}$ & $\begin{array}{l}\text { Std. } \\
\text { Dev. }\end{array}$ \\
\hline$p_{8}(y)$ & -3975.1 & 439.3 & -3758.4 & 529.3 & -3729.7 & 96.325 & -3922.73 & 88.61857 \\
\hline$p_{9}(y)$ & 0 & 0 & 0 & 0 & 2.101 & 1.508 & 3.677 & 1.0365 \\
\hline$p_{10}(y)$ & $2.66 \mathrm{E}-16$ & $1.59 \mathrm{E}-15$ & $3.138 \mathrm{E}-15$ & $1.975 \mathrm{E}-15$ & $8.79 \mathrm{E}-16$ & $1.17 \mathrm{E}-31$ & $1.21 \mathrm{E}-06$ & $9.37 \mathrm{E}-07$ \\
\hline$p_{11}(y)$ & 0 & 0 & 0.053819 & 0.13725 & $9.89 \mathrm{E}-02$ & $5.29 \mathrm{E}-2$ & 0.281 & 0.1086 \\
\hline$p_{12}(y)$ & $2.97 \mathrm{E}-2$ & $2.43 \mathrm{E}-2$ & $1.364 \mathrm{E}-06$ & $1.096 \mathrm{E}-6$ & $2.13 \mathrm{E}-29$ & 6.37E-29 & $1.9 \mathrm{E}-3$ & $1.3 \mathrm{E}-3$ \\
\hline$p_{13}(y)$ & 0.1483 & 0.1124 & $5.793 \mathrm{E}-06$ & $5.932 \mathrm{E}-6$ & 4.49E-22 & $2.06 \mathrm{E}-21$ & $8.3 \mathrm{E}-3$ & $5.1 \mathrm{E}-3$ \\
\hline \multirow[t]{2}{*}{ Function } & \multicolumn{2}{|c|}{ PSOGSA } & \multicolumn{2}{|c|}{ CamWOA } & \multicolumn{2}{|c|}{ GSA } & \multicolumn{2}{|c|}{ MFO } \\
\hline & $\begin{array}{l}\text { Avg. } \\
\text { value }\end{array}$ & $\begin{array}{l}\text { Std. } \\
\text { Dev. }\end{array}$ & Avg. value & $\begin{array}{l}\text { Std. } \\
\text { Dev. }\end{array}$ & Avg. value & $\begin{array}{l}\text { Std. } \\
\text { Dev. }\end{array}$ & Avg. value & $\begin{array}{l}\text { Std. } \\
\text { Dev. }\end{array}$ \\
\hline$p_{8}(y)$ & -3271.6 & 278.08 & -7339.503 & 947.30664 & -1694.53 & 190.6721 & -3329.13 & 288.317 \\
\hline$p_{9}(y)$ & 23.281 & 12.968 & 0 & 0 & 1.392 & 1.214 & 12.8372 & 7.352 \\
\hline$p_{10}(y)$ & $4.94 \mathrm{E}-12$ & $2.26 \mathrm{E}-12$ & $8.88 \mathrm{E}-16$ & 0 & $1.28 \mathrm{E}-10$ & $6.71 \mathrm{E}-11$ & $8.88 \mathrm{E}-16$ & $1.00 \mathrm{E}-31$ \\
\hline$p_{11}(y)$ & 0.2004 & 0.1141 & 0 & 0 & $1.67 \mathrm{E}-2$ & $2.79 \mathrm{E}-2$ & $1.78 \mathrm{E}-01$ & 8.43E-02 \\
\hline$p_{12}(y)$ & 0.2491 & 0.581 & 0.0022626 & 0.0032692 & $7.95 \mathrm{E}-21$ & $3.23 \mathrm{E}-21$ & $3.11 \mathrm{E}-02$ & $9.487 \mathrm{E} 2$ \\
\hline$p_{13}(y)$ & $3.11 \mathrm{E}-21$ & $1.06 \mathrm{E}-21$ & 0.0086723 & 0.0068672 & $5.67 \mathrm{E}-20$ & $1.88 \mathrm{E}-20$ & $1.10 \mathrm{E}-3$ & $3.33 \mathrm{E}-3$ \\
\hline \multirow[t]{2}{*}{ Function } & \multicolumn{2}{|c|}{ GA } & \multicolumn{2}{|c|}{ PSO } & \multicolumn{2}{|c|}{ DA } & \multicolumn{2}{|c|}{ WCA } \\
\hline & Avg. value & $\begin{array}{c}\text { Std. } \\
\text { Dev. }\end{array}$ & Avg. value & $\begin{array}{l}\text { Std. } \\
\text { Dev. }\end{array}$ & Avg. value & $\begin{array}{c}\text { Std. } \\
\text { Dev. }\end{array}$ & $\begin{array}{l}\text { Avg. } \\
\text { value }\end{array}$ & $\begin{array}{c}\text { Std. } \\
\text { Dev. }\end{array}$ \\
\hline$p_{8}(y)$ & -3692.9 & 182.42 & -2742.78 & 274.7175 & -3213.66 & 431.748 & -3422.55 & 304.572 \\
\hline$p_{9}(y)$ & $3.8 \mathrm{E}-4$ & $3.2 \mathrm{E}-4$ & 1.757 & 1.1592 & 11.561 & 10.177 & 20.993 & 10.524 \\
\hline$p_{10}(y)$ & $8.88 \mathrm{E}-16$ & $1.0 \mathrm{E}-31$ & $8.88 \mathrm{E}-16$ & $1.00 \mathrm{E}-31$ & $3.14 \mathrm{E}-05$ & $1.7 \mathrm{E}-04$ & $2.42 \mathrm{E}-15$ & $1.79 \mathrm{E}-15$ \\
\hline$p_{11}(y)$ & $5.6 \mathrm{E}-2$ & $3 \mathrm{E}-2$ & 0.1244 & $8.04 \mathrm{E}-2$ & 0.3846 & 0.3826 & 0.1502 & $9.44 \mathrm{E}-2$ \\
\hline$p_{12}(y)$ & $5.73 \mathrm{E}-05$ & $1.4 \mathrm{E}-4$ & $4.71 \mathrm{E}-32$ & $1.67 \mathrm{E}-47$ & 0.5296 & 0.6912 & $1.036 \mathrm{E}-2$ & $5.67 \mathrm{E}-2$ \\
\hline$p_{13}(y)$ & $6.21 \mathrm{E}-05$ & $1.1 \mathrm{E}-4$ & $1.34 \mathrm{E}-32$ & $5.56 \mathrm{E}-48$ & 0.5292 & 0.7173 & $7.3 \mathrm{E}-4$ & $2.7 \mathrm{E}-3$ \\
\hline
\end{tabular}

The 7 uni-modal functions $p_{1}-p_{7}$ are employed in the present work as revealed by Table- 1 for testing the exploitation capability of the algorithm in the present work. Statistical results in 30 runs of SCiWOA and WOA are evaluated with the outputs of other 10 existing methods [12] and listed in Table 3. The performances of all the 7 test functions are found to better through the proposed algorithm in comparison to original WOA technique. Thus, the proposed control strategy (SCiWOA) is found to be better than all other meta heuristic optimization methods (i.e. $\left.p_{1}(y), p_{2}(y), p_{3}(y), p_{4}(y), p_{7}(y)\right)$ among 7 uni-modal functions.

\section{B. Evaluation and analysis of exploration capacity $\left(p_{8}(y)-p_{13}(y)\right)$}

Multimodal functions are appropriate for testing the exploration capacity as they use a number of relative optima. The processes and statistical outcomes are shown in Table 2 and 4 respectively. It is perceived from Table 4 that SCiWOA for functions $p_{8}(y), p_{9}(y), p_{10}(y)$, $p_{11}(y)$ performs better and produce better results in comparison to other algorithms. 


\section{Convergence Analysis}

Search agents in SCiWOA attempt to create a wide search in its space and hit the finest point. They are modified suddenly in the beginning step of search route and then converge gradually. The Convergence characteristics of SCiWOA are compared with those of WOA as shown in Fig. 1 for some functions considering 6 search agents and 100 iterations for a better illustration. It is clear from Fig. 1 (a) that, for test function $p_{1}(y)$, it takes about 30 iteration for WOA technique to converge whereas SCiWOA takes about 5 iterations to converge. The test function $\mathrm{p}_{2}(\mathrm{y})$, it take about 5 iteration for WOA and less than 5 iteration in case of WCiWOA technique to converge. For test functions $\mathrm{p}_{3}(\mathrm{y})$ and $\mathrm{p}_{4}(\mathrm{y})$, WOA technique takes more than 100 iteration to converge whereas SCiWOA takes less than 10 iterations to converge. In the test function $\mathrm{p}_{9}(\mathrm{y})$ and $\mathrm{p}_{10}(\mathrm{y})$ the convergence WOA it takes more than 100 iteration for the case of $\mathrm{p}_{9}(\mathrm{y})$ and 55 iteration take in case of test function $\mathrm{p}_{10}(\mathrm{y})$ but both the cases less than 5 iteration to converge in SCiWOA technique. Similarly in the test function $\mathrm{p}_{11}(\mathrm{y})$ and $\mathrm{p}_{12}(\mathrm{y})$ iteration about 30 and 25 respectively for WOA technique whereas iteration value less than 5 to converge in both the test functions in SCiWOA technique. It is observed that convergence nature of SCiWOA is improved in comparison to WOA in virtually all functions
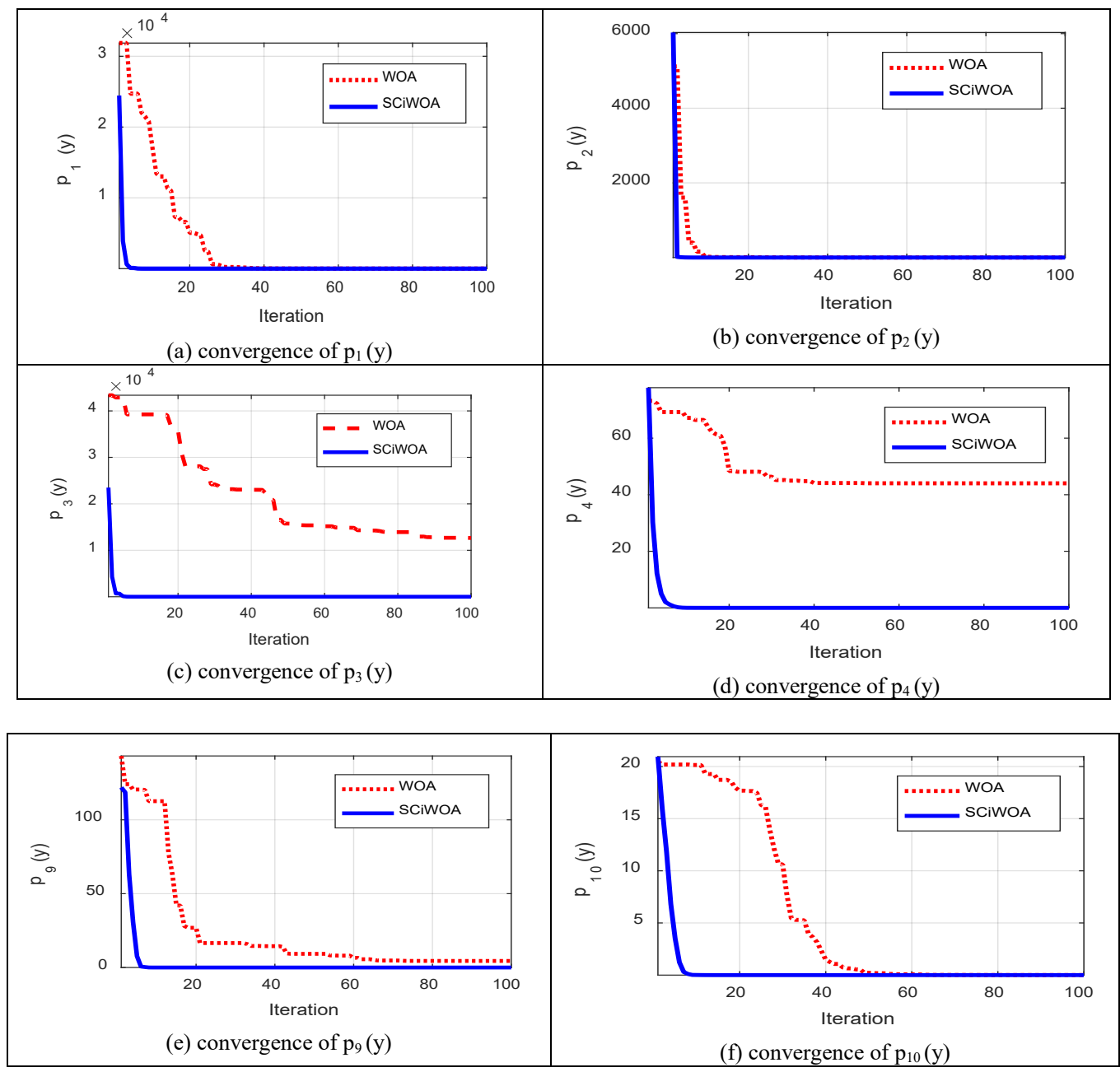


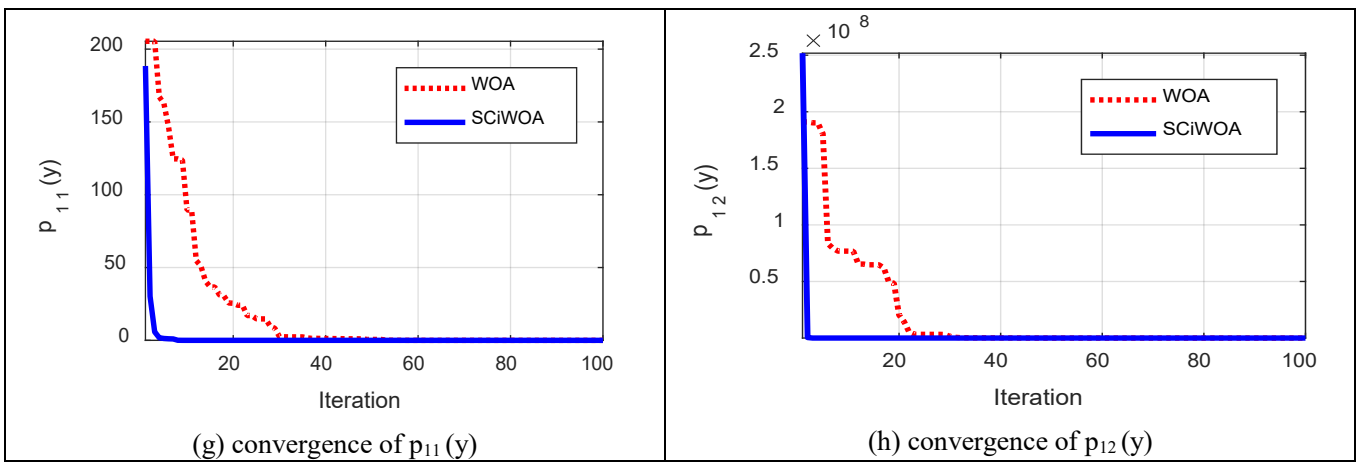

Figure 1. Comparison of convergence characteristics of some test functions with WOA and SCiWOA techniques

\section{System Under Study}

The proposed SCiWOA technique is tried for the problems of physical world like selection of the adaptive fuzzy logic controller parameter for frequency regulation of hybrid power system with storage elements as presented in Fig. 2.

Parameters of the proposed DPGS system studies [24, 26-28]

Solar PV parameters: $\quad \mathrm{KPV}=1.0, \mathrm{TPV}=1.8 \mathrm{~s}$,

WTG parameters: $\quad \mathrm{KWTG}=1.0, \mathrm{TWTG}=1.0 \mathrm{~s}$,

FC parameters: $\quad \mathrm{KFC}=0.01, \mathrm{TFC}=4.0 \mathrm{~s}$

DEG parameters: $\quad \mathrm{KDEG}=0.003, \mathrm{TDEG}=2.0 \mathrm{~s}$,

AE parameters: $\quad \mathrm{KAE}=0.002, \mathrm{TAE}=0.5 \mathrm{~s}$,

BESS parameters: $\quad$ KBESS $=-0.003$, TBESS $=0.1 \mathrm{~s}$,

FESS parameters: $\quad$ KFESS $=-0.01$, TFESS $=0.1 \mathrm{~s}, \mathrm{Kn}=0.6$

In the present work SCiWOA technique is proposed against physical world problems such as selection of parameters of adaptive fuzzy logic controller (FLC) for frequency regulation of the dispersed power system(DPS) with storage elements. The system consists of sources like Wind Turbine Generator(WTG), Diesel Engine Generator (DEG ), Fuel-cell (FC), Aqua Electrolysers (AE), Battery Energy Storage System(BESS), Flywheel Energy Storage System (FESS), Electric Vehicle (EV), Solar Photovoltaic (SPV), etc. [24-26]. The supply to the load is the summation of outputs of the above systems. The aqua-electrolyser absorbs the fluctuations of WTG and produces hydrogen gas which is used as input to the fuel cell. Outputs of solar PV and wind turbine systems are intermittent and unpredictable as these sources are purely seasonal and dependant on climatic and geographical situations. Therefore, it is a challenge to maintain power balance and system stability which can be done by proper co-ordination between stability and control of power output. To assure simple control, minimum maintenance, design flexibility along with an improved performance of the dispersed power system partially decentralized controller is considered for all its subsystems in place of centralised/decentralised controller including limiters to each of them for emulating changes in electro-mechanical characteristics in respective subsystem. A delay of $10 \mathrm{msec}$ is associated with the input and output signals and the control participation factors of controllable sources are represented by CPFs. 


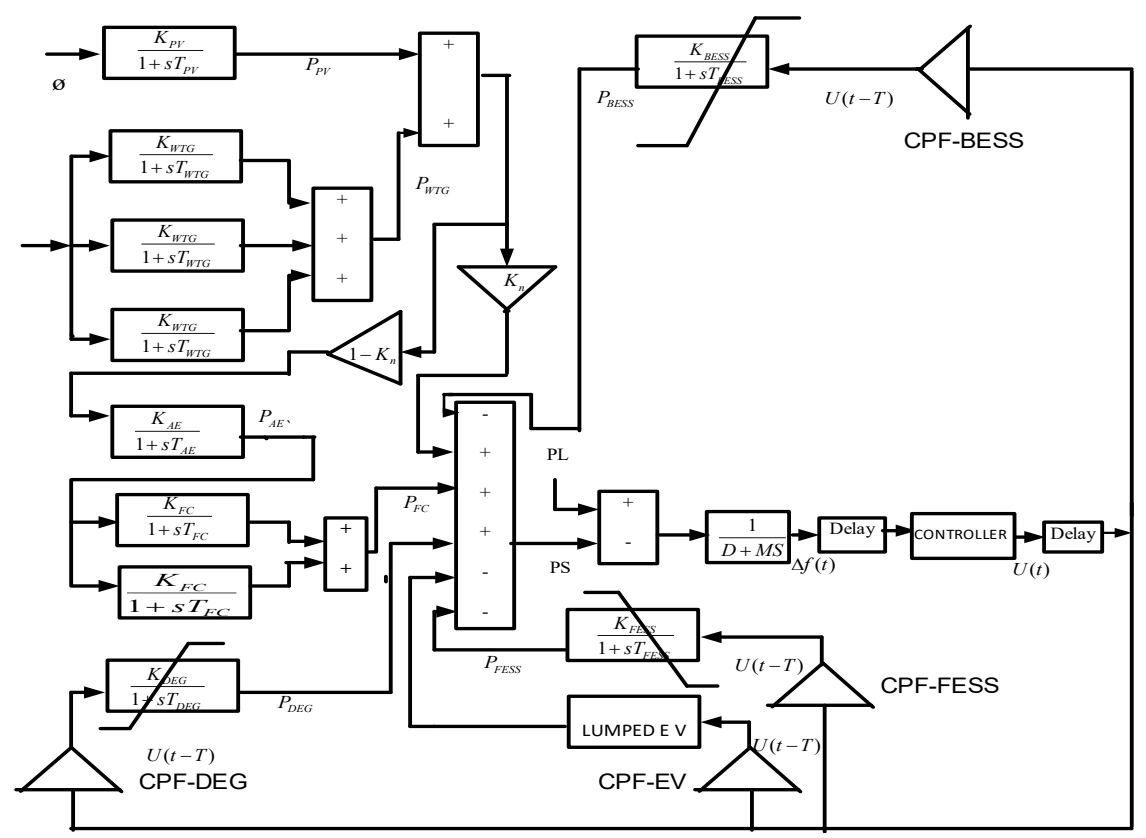

Figure 2. Block diagram of DPS under study

\section{A. System Modelling}

\section{A.1. Wind turbine generator (WTG) system}

This system is associated with several nonlinearities. It uses pitch controller to counteract to frequency oscillation of the utility grid. The pitch angle and output of WTG varies according to the wind speed.

Wind power output is given by

$$
P_{W P}=\frac{1}{2} \rho A_{R} C_{P} V_{W}^{3}
$$

The transfer function is given by

$$
G_{W T G_{N}}(s)=\frac{K_{W T G}}{1+s T_{W T G}}=\frac{\Delta P_{W T G}}{\Delta P_{W P}}
$$

Where, $N=$ number of units $=1,2,3$

\section{A. 2. Solar PV system}

Now a day's worldwide research on solar power is being explored by researchers to derive optimum energy utility as the power supplied through this system is gaining more visibility in parallel to the steady increase in world's energy demand. As per the current study, solar power tower efficiency is about $13 \%$, sunlight collection and heat absorption is about $70 \%$ and conversion efficiency of PV cell is about $10 \%$. The frequent change in weather along with rotation of day and night demand the storage technology to supply continuous energy. Solar plants are best suited for utility scale implementation in the range of 30MW to 400MW.

Output Power of PV system can be expressed as

$$
P_{P V}=\eta \cdot S \cdot \varphi\left[1-0.005\left(T_{a}+25\right)\right]
$$

Where, $\eta=\mathrm{PV}$ cell conversion efficiency with a value of $10 \%, S=\mathrm{PV}$ array area with a value of $4084 \mathrm{~m}^{2}$ $\varphi=$ solar irradiation in $\mathrm{kW} / \mathrm{m}^{2}, \mathrm{~T}_{\mathrm{a}}=$ ambient temperature in degree Celsius

First order transfer function of this system during low frequency domain analysis is given by 


$$
G_{P V}(s)=\frac{K_{P V}}{1+s T_{P V}}=\frac{\Delta P_{P V}}{\Delta \varphi}
$$

\section{A. 3. Aqua electrolyser (AE)}

Aqua electrolyser absorbs the fluctuating power output of solar PV and wind turbine generator. In this system electric current is passed to two electrodes spaced in aqueous electrolyte by which hydrogen is generated for power generation. The transfer function of $\mathrm{AE}$ is given by

$$
G_{A E}(s)=\frac{K_{A E}}{1+s T_{A E}}=\frac{\Delta P_{A E}}{U_{2}}
$$

\section{A. 4. Fuel cell (FC)}

As a substitute of conventional generators fuel cell produces electric power by electro chemical reaction between Oxygen and Hydrogen. It is a higher order model with nonlinearities and produces small d.c voltage which is converted into a.c through dc/ac converter. Cells are combined in series/parallel circuits to produce enough voltage. When analysis is in low frequency domain, the $1^{\text {st }}$ order transfer function of this system is given by

$$
G_{F C_{N}}(s)=\frac{K_{F C}}{1+s T_{F C}}=\frac{\Delta P_{F C}}{\Delta P_{A E}}
$$

The values of ' $\mathrm{N}$ 'is taken as $\mathrm{N}=1,2$

\section{A. 5. Diesel Engine Generator (DEG)}

It is a nonlinear system which is capable to supply the shortage of power by producing a torque to drive an alternator. It can reduce the power mismatch between supply and load demand independently. Its prime mover is designed to have faster dynamic response. It is also capable of disturbance rejecting disturbances in order to meet the uncertainty in load demand. The following first order transfer function explain the relationship between fuel consumption and mechanical power given by

$$
G_{D E G}(s)=\frac{K_{D E G}}{1+s T_{D E G}}=\frac{\Delta P_{D E G}}{\Delta U}
$$

\section{A. 6. Storage system}

(i) Flywheel Energy Storage System (FESS):

FESS is used to balance the power fluctuation developed by WTG and SPV systems. It is more reliable and equipped with longer life, faster response at comparatively less cost in comparison to other energy storage systems and are designed for high and low speed operations. It stores energy in rotating flywheel mechanically which is converted to electrical energy and delivered to the load when the fly wheel is rotated using a motor. Energy stored in the fly wheel given by $\left(\mathrm{E}=\frac{1}{2} l w^{2}\right)$ varies linearly with moment of inertia(l) and square of the angular velocity $\left(\omega^{2}\right)$. Higher mass, volume and losses with less stored energy per volume are main drawbacks of this system. Its transfer function is given as

$$
G_{F E S S}(s)=\frac{K_{F E S S}}{1+s T_{F E S S}}=\frac{\Delta P_{F E S S}}{\Delta U}
$$

(ii) Battery Energy Storage System (BESS):

By this system huge amount energy can be stored from solar and wind in less time which can be supplied it for a longer period. It acts as a source or as load to provide stable operation as per the requirement. It is equipped with a power converter along with a battery bank. A number of modules are incorporated into this system to achieve higher power capacity. This 
system is coupled with electric vehicles energized by controller signal. The components of the storage elements work in nonlinear zone due to the presence of rate constraints which also manage the electromechanical characteristics and prevent the mechanical shock.

These nonlinearities and saturations are given by

$$
\begin{aligned}
& \left|\overrightarrow{P_{F E S S}}<0.09\right|,\left|\dot{P_{B E S S}}<0.09\right|,\left|\overrightarrow{P_{D E G}}<0.01\right|, \quad\left|\dot{P_{E V}}<0.01\right|,\left|P_{F E S S}<0.9\right|,\left|P_{B E S S}<0.2\right|, \\
& \left|P_{E V}<0.8\right| \text { and } 0 \leq P_{D E G} \leq 0.45 .
\end{aligned}
$$

The transfer function of this system is given by

$$
G_{B E S S}(s)=\frac{K_{B E S S}}{1+s T_{B E S S}}=\frac{\Delta P_{B E S S}}{\Delta U}
$$

\section{A. 7. Electric vehicle (EV)}

Electric vehicles are used in hybrid power systems for improving stability against fluctuations in load demands. They consume real power during charging and supply during discharging. It has a battery replacing the petrol tank and an electric motor replacing an I.C engine. It costs less and can reduce emissions. EVs are basically of two types, e.g (i) all electric vehicle (AEVs) and (ii) plug in electric vehicle (PHEVs). The former includes battery electric vehicle (BEVs) and fuel cell electric vehicles (FCEVs). Each of them is partially charged through regenerative braking. Electricity is generated by EVs from the energy lost due to braking.

$\Delta U=\mathrm{LFC}$ signal fed to EV. $\pm B k W=$ battery capacity of EV and $T_{P H E V}=$ time constant of EV. $E=$ current battery energy controlled within $E_{\min }=80 \%$ and $E_{\max }=90 \%$.

$K_{1}$ and $K_{2}$ mismatch in energy given by $K_{1}=E-E_{\max }, K_{2}=E-E_{\min }$.

When the charge hits the limiting values there is no participation of EV's in AGC. The net battery stored energy is calculated by the stored energy subsystem in a local control centre [27] that acts as link between power grid and EVs.

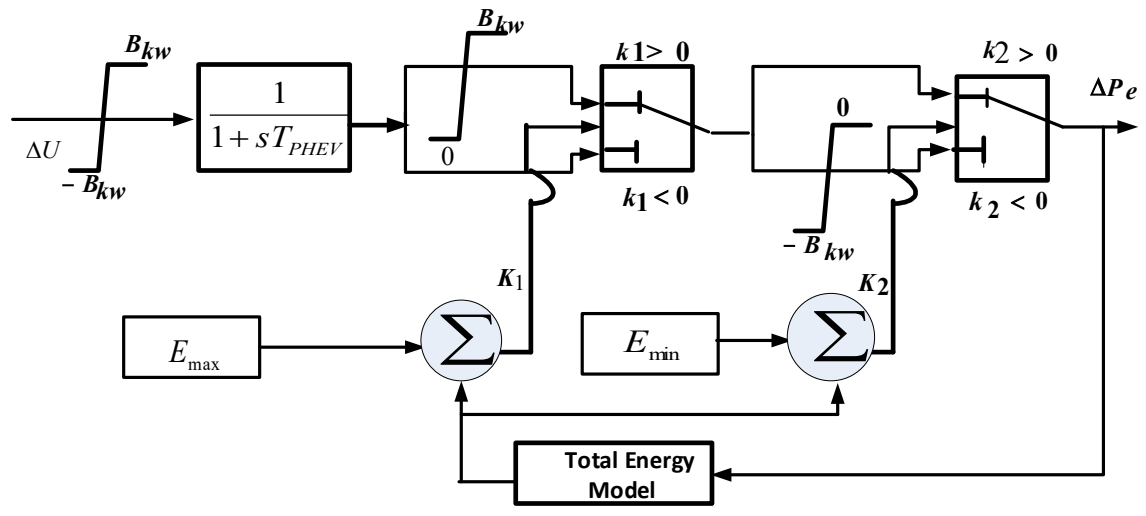

Figure 3. Modelling of electric vehicle for LFC study

The EVs which are ready to contribute power to the grid are engaged as a lumped model for the frequency control scheme. In addition, the LFC signal is sent to the EVs according to their state of charge (SOC) for charging or discharging purpose. The LC (local control) centres act as the link between the central load dispatching centre (CLDC) and the EV. The charging and discharging of the EV count on its SOC while SOC is vastly reliant on the LFC signal which CLDC dispatches. When the SOC hits the limiting values, the EV stops participating in LFC.

A. 8. Model of the Dispersed Power System

The transfer function of the system under study is expressed by 


$$
G(s)=\frac{\Delta f}{\Delta P}=\frac{1}{D+s M}
$$

Were,

$D=$ characterises damping constant,

$\Delta P=$ deviation in power

$M=$ inertia constant of DPGS system,

$\Delta f=$ frequency deviation

\section{B. Combined fuzzy PID controller}

The main objective of (FLC) is to preserve damping characteristics with minimum steady state error. The designing process needs appropriate adjustments of membership function, design and control of tuning procedures. The online tuning of membership function leads to complicacy as it comprises with fixed scaling factors and needs heavy computations. An alternative method may be adopted for designing the FLC using PID controller to optimize gains and input scaling factors. The adaptive fuzzy PID (FPID) controller as shown in Fig.4. In this case scaling factors can be selected during operating stage of the controller. The controller can remove steady state error, handle nonlinearities and provide quick response. There is no direct link between inputs to this controller. Therefore, performance of the controller may not be satisfactory. In a view to neutralize the above limitations the input is given directly to the controller and passed through fuzzy to make the system adaptive.

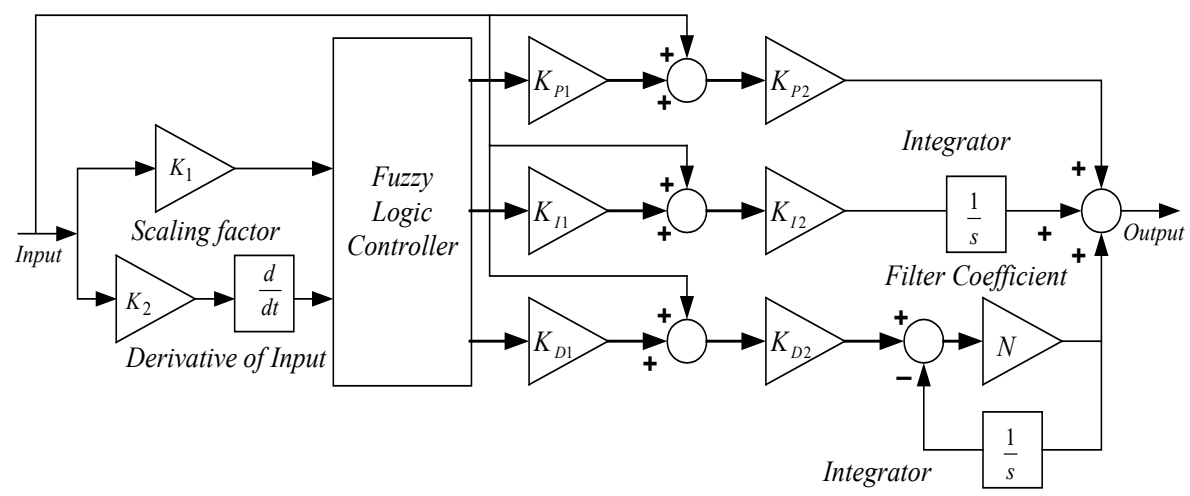

Figure 4. Adaptive Fuzzy PID controller

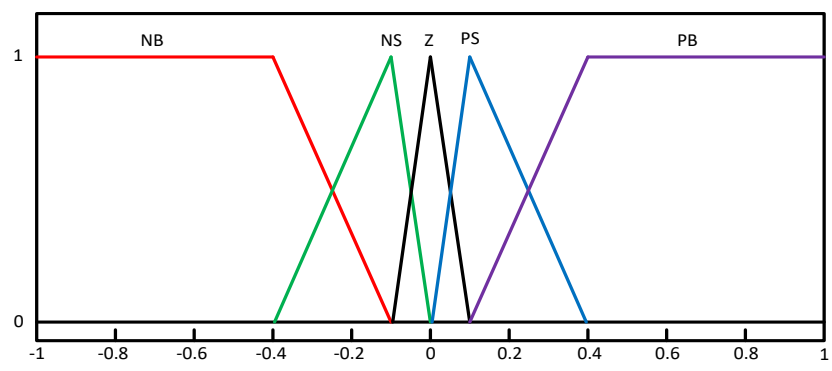

Figure 5. Membership function of error and change of error of combined fuzzy PID controller

The controller performance can be improved by updating the output continuously through adaptive tuning of scaling factors with fuzzy rule base. For this purpose, five triangular 
membership functions with a set of fixed control rules are considered in the controller as shown in figure 5 .

Table 5. Fuzzy rule base for AFPID

\begin{tabular}{|c|c|c|c|c|c|}
\hline Neg Big & Neg Big & Neg Small & Zero & Pos Small & Pos Big \\
\hline Neg Small & Neg Big & Neg Small & Neg Small & Zero & Pos Small \\
\hline Zero & Neg Small & Neg Small & Zero & Pos Small & Pos Small \\
\hline Pos Small & Neg Small & Zero & Pos Small & Pos Small & Pos Big \\
\hline Pos Big & Zero & Pos Small & Pos Small & Pos Big & Pos Big \\
\hline
\end{tabular}

Variables assigned to membership functions are PosBb (Positive Big), PosSm (Positive Small), Zero, NegSm (Negative Small) and NegBg (Negative Big) as shown in table-5. Frequency errors and change in frequency errors are considered as controller input. Output-Input scaling factors are tuned by using SCiWOA. During positive-small and positive-big input errors, the rule prevents a large undershoot and provides positive-big output. During negative-big and zero error the frequency overshoot is reduced significantly which in turn give rise to negativesmall output.

The objective is expressed by ISE criteria along with the controller output $(\Delta u)$ for minimization of frequency deviation $(\Delta f)$. It is given by

$$
J=\int_{0}^{T}\left[(\Delta f)^{2}+(\Delta U)^{2} / k n\right] \cdot d t
$$

Where, $\mathrm{Kn}=5$ makes both terms of equation- 24 competitive at the time of optimization process. Different parameters along with scaling factors of the controller are selected by SCiWOA. Entry of control signal to subsystems in minimized form ensures the need of low power to Battery and EV, fewer jerks to Flywheel and DEG and low consumption of Diesel. Using gain updating factor the proposed partially decentralized combined fuzzy PID (PDCFPID) controller receives the input signal and modifies the output scaling factor continuously. Controller output is fed to the controllable sources through control participation factor (CPF) for modification of their power outputs. CPFs of each controllable source and controller parameters are tuned by SCiWOA technique.

\section{Simulation of Experimental Results and Discussions}

The competency of the suggested SCiWOA approach is studied with PID, CFPID and PDCFPID controllers in simulink environment for the of DPGS system. Controller's parameters are optimized by the said approach and outcomes are compared to demonstrate the superiority of the proposed controller. The variation pattern of load demand $\left(\mathrm{P}_{\mathrm{d}}\right)$ is shown in Fig. 6 (a). The PVcell power output $\left(\mathrm{P}_{\mathrm{PV}}\right)$ is given by Equation (17-19). The wind generator $\left(\mathrm{P}_{\mathrm{WTG}}\right)$ and solar power are shown in Figures 6 (b) and (c). Variation of their outputs causes' system frequency fluctuation leading to which is to be put an end by suitable controller action.

Table- 6 gives results of SCiWOA and WOA optimized PID, CFPID and PD-CFPID controller parameters. As shown in Table- 8 the optimized value of objective function is found to be $810.369 \times 10^{-2}$ with application of WOA approach for PID controller. This value is reduced to $794.696 \times 10^{-2}$ with SCiWOA approach. Hence, it is concluded that the performance of PID controller is better with SCiWOA technique in comparison to WOA technique. The objective function is again reduced to $781.474 \times 10^{-2}$ by performing through CFPID controller using SCiWOA. However, the superiority is imposed by the proposed PD-CFPID controller whose application significantly reduces this value to $362.019 \times 10^{-2}$ with the same technique 


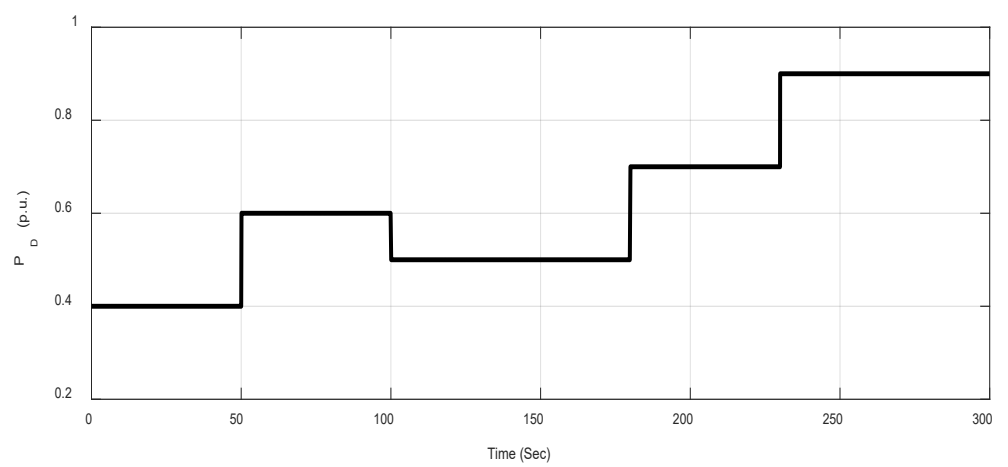

(a)

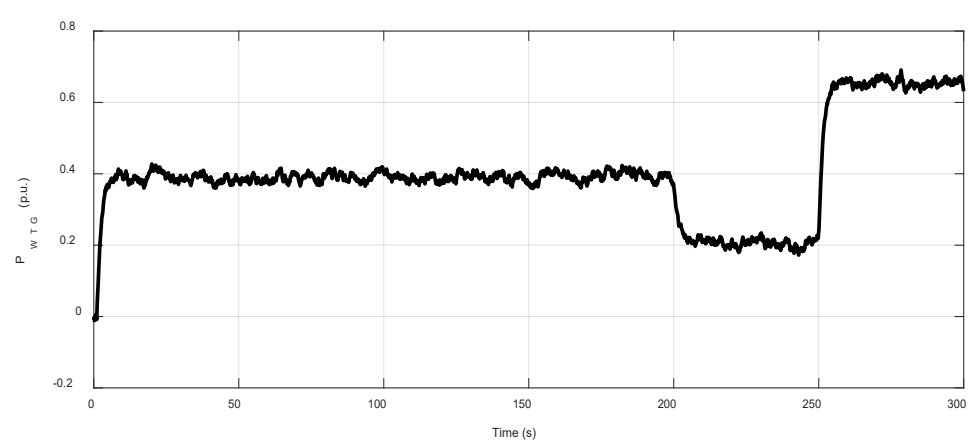

(b)

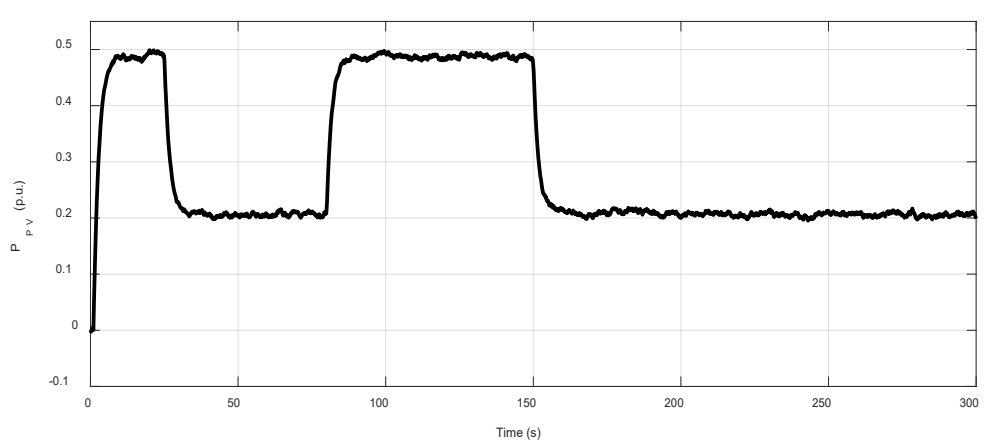

(c)

Figure 6 (a) variation of pattern of load demand (b) wind power (c) Solar power which are independent of the controller structure

\section{Case-1: Normal operation}

In this case, Generations from solar and wind sources along with the load pattern are shown in Figure 6. Dynamic responses with the proposed SCiWOA optimized PID, CFPID and PDCFPID are presented in Figure 7. From Figure 7(a) it is found that ,the performance of system with PD-CFPID is better than that through PID and CFPID controllers. The power outputs with proposed PD-CFPID controller are shown in Figures. 7 (b)-(c). Power demand and supply of the system should be same with all variations varied at different time. The total generation is obtained by adding the power generation from the renewable sources less than the power by adding power aqua electrolyzer, DEG and fuel cell. For example, at the time $t=50 \mathrm{sec}$ it can be seen from 6 (a) that the demand power is more than the total renewable powr. Thus the storage units like BESS, 
Pabitra Mohan Dash, et al.

FESS, and electric vehicle (EV) gives less power to meet the power demand.Hence the power equilibrium is maintained and the system is frequency stable.

Following cases are taken into assumption to assess performances of the system: -

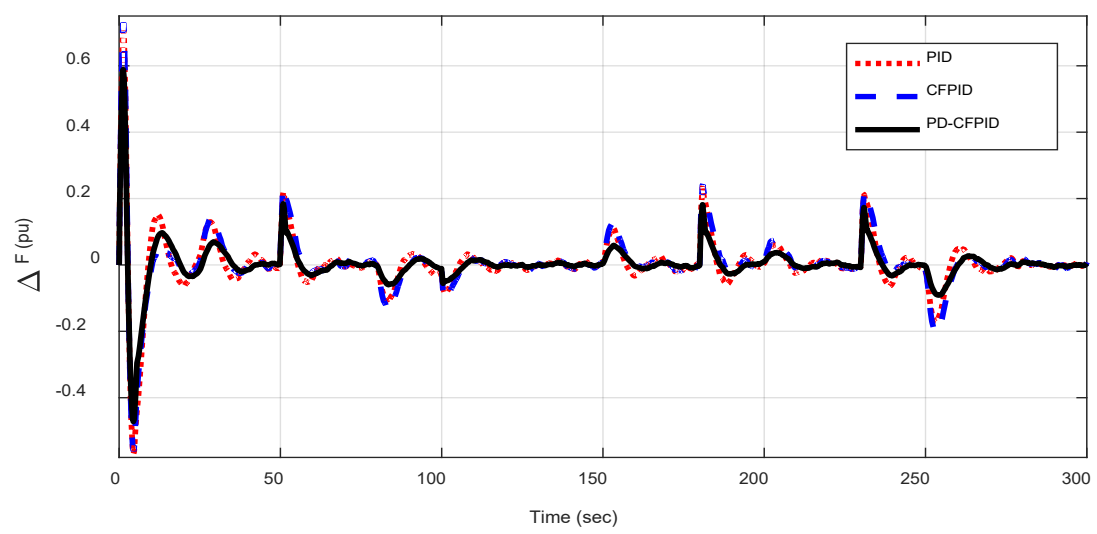

(a)

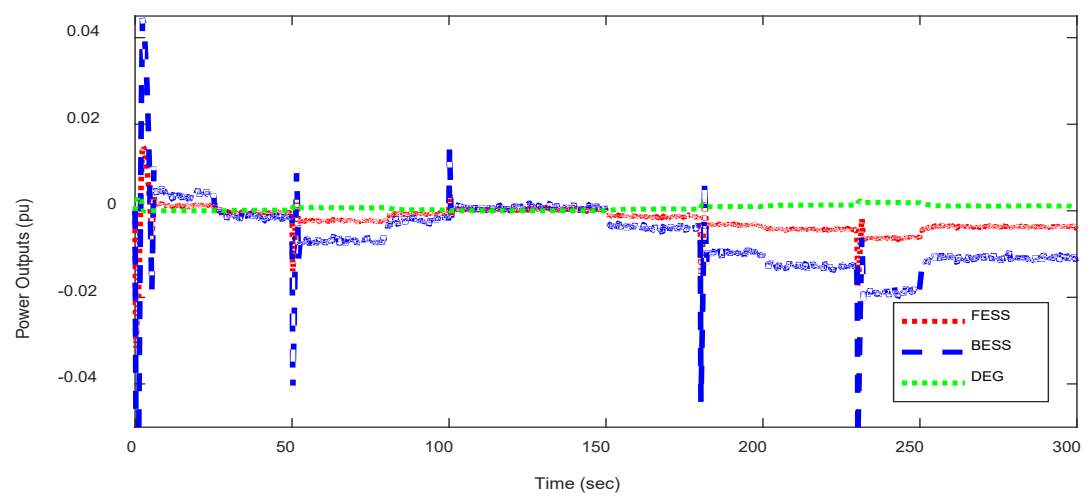

(b)

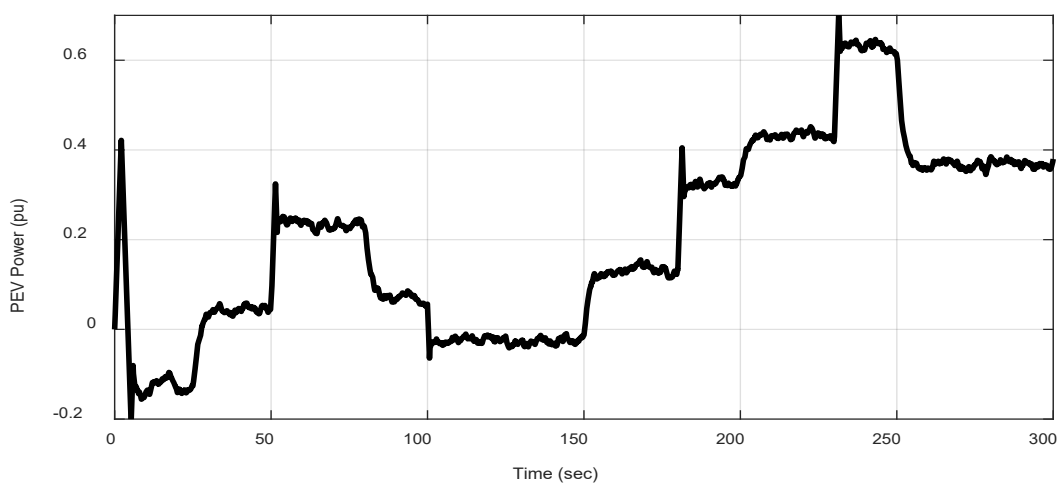

(c)

Figure 7 System response for case 1 (a) frequency deviation (b) power outputs of FESS, BESS and DEG (c) power of electric vehicle 
Table 6. Optimized parameters

\begin{tabular}{|c|c|c|}
\hline Technique/Controller & Optimization parameters & Objective function $(\mathrm{J})$ \\
\hline WOA: PID & $\mathrm{K}_{\mathrm{P}}=0.6020, \mathrm{~K}_{\mathrm{I}}=0.4202, \mathrm{~K}_{\mathrm{D}}=1.0641$ & $810.369 \times 10^{-2}$ \\
\hline SCiWOA: PID & $\mathrm{K}_{\mathrm{P}}=0.6624, \mathrm{~K}_{\mathrm{I}}=0.3437, \mathrm{~K}_{\mathrm{D}}=1.5351$ & $794.696 \times 10^{-2}$ \\
\hline SCiWOA: CFPID & $\mathrm{K}_{1}=0.9997, \mathrm{~K}_{2}=0.1365$ & $781.474 \times 10^{-2}$ \\
& $\mathrm{~K}_{\mathrm{P} 1}=1.5204, \mathrm{~K}_{\mathrm{I}}=0.9702, \mathrm{~K}_{\mathrm{D} 1}=0.0901$ & \\
\hline SCiWOA: PD-CFPID & $\mathrm{K}_{\mathrm{P} 2}=0.2474, \mathrm{~K}_{\mathrm{I}}=0.423, \mathrm{~K}_{\mathrm{D} 2}=1.1027$ & \\
& $\mathrm{~K}_{1}=1.9964, \mathrm{~K}_{2}=1.7787$ & \\
& $\mathrm{~K}_{\mathrm{P} 1}=1.8963, \mathrm{~K}_{\mathrm{I}}=0.9575, \mathrm{~K}_{\mathrm{D} 1}=1.9991$ & \\
& $\mathrm{~K}_{\mathrm{P} 2}=0.1009, \mathrm{~K}_{12}=0.9104, \mathrm{~K}_{\mathrm{D} 2}=1.9964$ & \\
& $\mathrm{CPF}-\mathrm{FESS}=1.9964 ;$ & \\
& $\mathrm{CPF}-\mathrm{BESS}=1.7787$ & \\
& $\mathrm{CPF}-\mathrm{DEG}=1.9987 ;$ & \\
& $\mathrm{CPF}-\mathrm{EV}=1.9787$ & \\
\end{tabular}

Case- 2: Uncertain Cases

PID controller is comparatively simple. Therefore, these are widely accepted in linear control system. But the gains are found to be suitable for limited problems. In case of various nonlinear and uncertain problems these conventional controllers fail to give robust adaptive response. In such cases fuzzy logic implementation can enhance the system performance by handling nonlinearities and uncertainties using FLC. To illustrate the efficacy of PD-CFPID over CFPID and PID controller, the performance are compared under various uncertain situations and following responses are obtained.

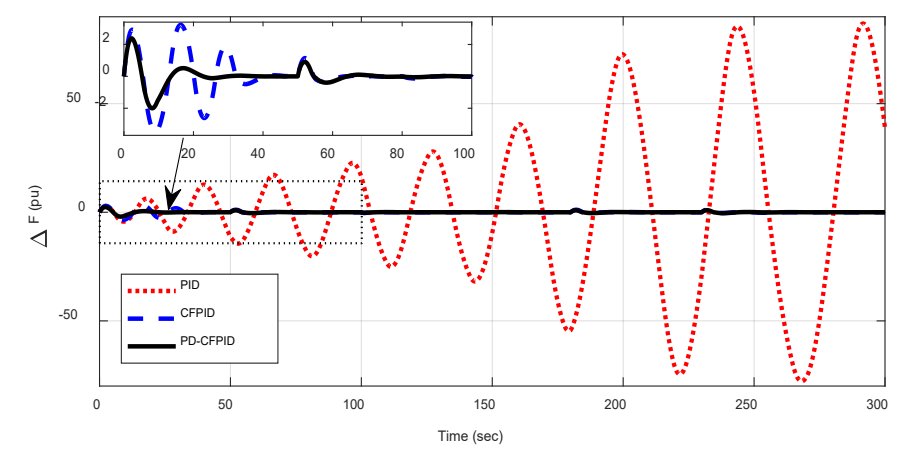

Figure 8(a). Comparison of PID, CFPID and PD-CFPID with increased load demand

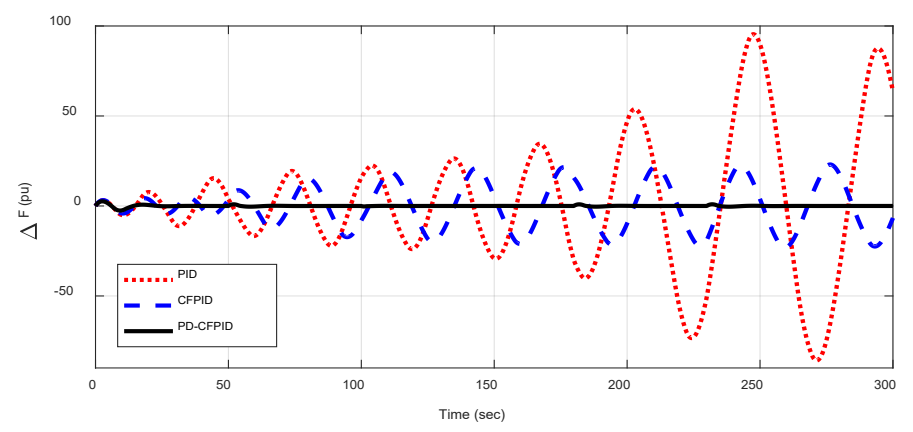

Figure 8(b). Comparison of PID, CFPID and PD-CFPID with increased load demand and decreased in solar and wind powers 


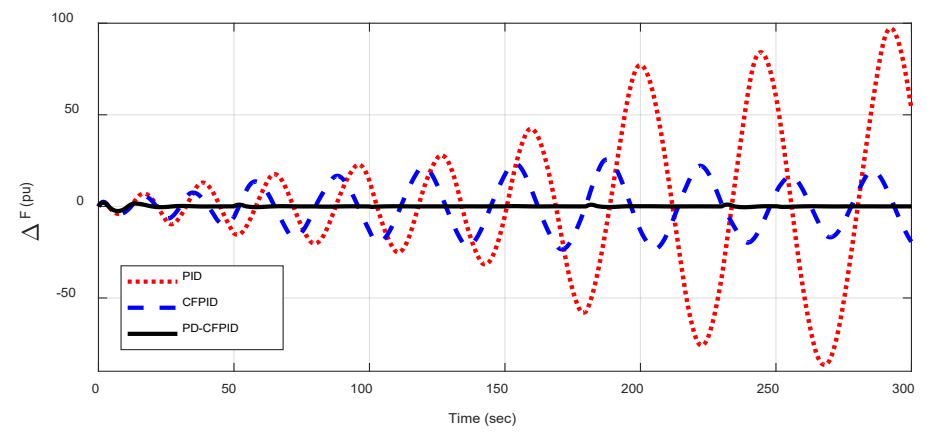

Figure 8(c). Comparison of PID, CFPID and PD-CFPID with increased load demand, solar and wind powers

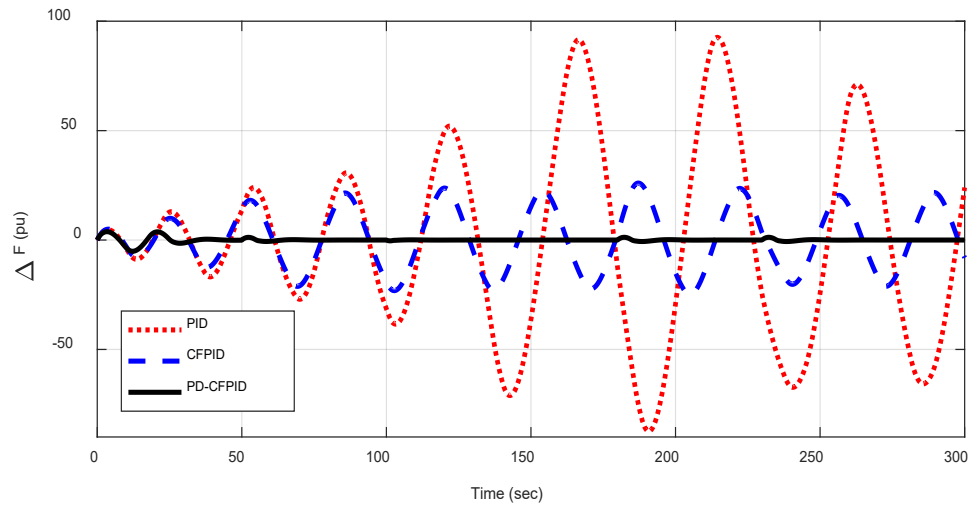

Figure 8(d). Comparison of PID, CFPID and PD-CFPID with increased load demand with unavailability of solar and wind powers

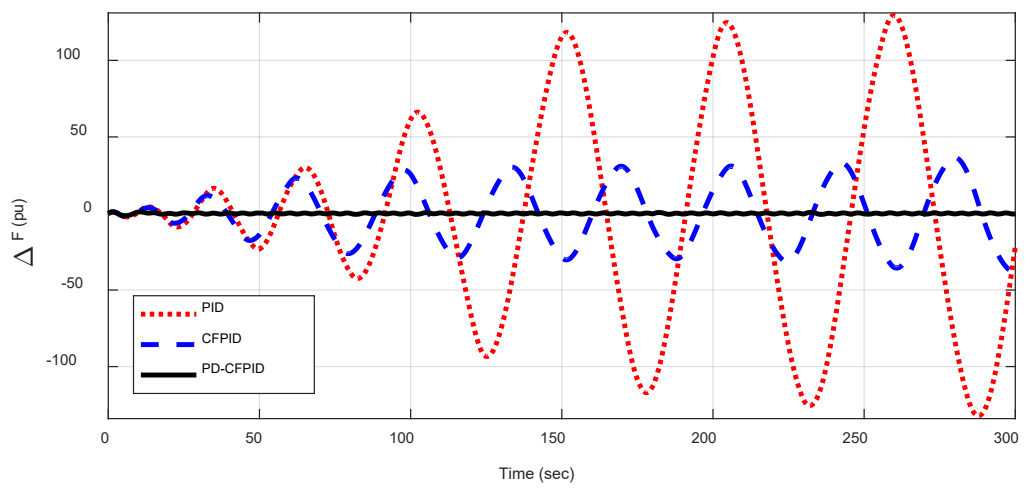

Figure 8(e). Comparison of PID, CFPID and PD-CFPID with increased time delay

Fig. 8 System response under various uncertain cases

Condition A: The demand of load pattern is increased by $150 \%$.

Condition B: The demand of load pattern is increased by $150 \%$. With $50 \%$ decrease in solar and wind powers

Condition C: Solar, wind powers and load demand pattern are enhanced by $150 \%$.

Condition D: $200 \%$ increase in load demand when solar and wind powers are not available Condition E: The time delay is raised to $400 \mathrm{~ms}$ 
Change in frequency level during above scenarios are presented in Figures 8(a)-(e). From Figure $8(\mathrm{a})$ it is observed from condition-A that, when demand in load pattern is increased by $150 \%$, the system is unstable with PID controller and system is upheld with both CFPID and PDCFPID. But the response degrades with CFPID under condition-A, but response remains unaffected with proposed PD-CFPID controller. For condition-B to E, the system is unstable with both PID and CFPID controllers as evident from Figures 8(b)-(e). However, the system stability is found to be maintained with the proposed PD-CFPID controller giving rise to a small margin in frequency variations.

\section{Conclusion}

A novel approach is taken in this work to implement computational technique sine cosine function adopted improved WOA (SCiWOA) for optimizing the controller parameter 'c' effectively and to solve the optimization problem. Scaling factors are considered to change the step size position updating formula of search agents during the iterations. Intensive simulations has been conducted and verified on test functions to evaluate the feasibility and effectiveness of SCiWOA. From the result it is found that SCiWOA provides better performance in comparison to ABC, GA, CamWOA, WCA, PSO, GSA, PSOGSA, MFO, DA and WCMFO methods in 5 out of 7 uni-modal and 4 out of 6 multimodal functions. A Partially Decentralized Combined Fuzzy PID (PD-CFPID) controller is tuned through the proposed technique to regulate frequency of the hybrid system consisting several renewable sources along with storage devices like battery, flywheel as well as plug in EVs in optimization process in presence of nonlinearities storage system rate constraints and time delays. It is concluded that SCiWOA tuned PD-CFPID controller outperforms and is superior to conventional PID and CFPID controllers and maintains frequency stability under various uncertain condition.

\section{References}

[1] Sayedali M, Lewis A. The whale optimization algorithm. Advances in Engineering Software. 2016; 95: 51-67.

[2] Ling Y, Zhou Y, Luo Q. Levy flight trajectory-based whale optimization algorithm for global optimization. IEEE Access. 2017; 6168 - 6186.

[3] $\mathrm{Hu} \mathrm{H}, \mathrm{Bai} \mathrm{Y}, \mathrm{Xu} \mathrm{T}$. Improved whale optimization algorithms based on inertia weights and their applications. International Journal of Circuits, Systems and Signal Processing. 2017; 11:12-26.

[4] Mafarja MM, Mirjalili S. Hybrid whale optimization algorithm with simulated annealing for feature selection. Neurocomputing. 2017; 260: 302-312.

[5] Sahu PR, Hota PK, Panda S. Modified whale optimization algorithm for fractional order multi-input SSSC based controller design. Optimal Control Application and Methods. 2018; 39: 1802-1817

[6] Sivalingam R, Chinnamuthu S, Dash S. A modified whale optimization algorithm based adaptive fuzzy logic PID controller for load frequency control of autonomous power generation systems. Journal for Control, Measurement, Electronics, Computing and Communications 2018; 58(4): 410-421.

[7] Bozorgi SM, Yazdani S. IWOA: An improved whale optimization algorithm for optimization problem. Journal of Computational Design and Engineering.2019; 6(3): 243259.

[8] Sudha KR., Raju YB, Sekhar AC. Fuzzy C-Means clustering for robust decentralized load frequency control of interconnected power system with generation rate constraint, Int. J. of Electrical Power and Energy Systems, 37 (2012) 58-66.

[9] Mohanty PK, Sahu BK, Pati TK, Panda S, Kar SK. Design and analysis of fuzzy PID controller with derivative filter for AGC in multi-area interconnected power system, IET Gener. Transm. Distrib.10 (2016) 3764-3776.

[10] Fereidouni A, Masoum AS, Moghbel M. A new adaptive configuration of PID type fuzzy logic controller, ISA Trans. 56 (2015) 222-240. 
Pabitra Mohan Dash, et al.

[11] Savino MM, Mazza A.Toward environmental and quality sustainability: an integrated approach for continuous improvement. IEEE Transactions on Engineering Management, 61 (2014) 171-181.

[12] Khalilpourazari S, Khalilpourazary S. An efficient hybrid algorithm based on water cycle and moth-flame optimization algorithms for solving numerical and constrained engineering optimization problems. Soft Computing. 23 (2019), 1699-1722.

[13] Digalakis J, Margaritis K. On benchmarking functions for genetic algorithms. Int J Comput Math. 77 (2001), 481-506.

[14] Yao X, Liu Y, Lin G. Evolutionary programming made faster. IEEE Trans Evol Comput. 3(2) (1999), 82-102.

[15] Karaboga D, Basturk B. A powerful and efficient algorithm for numerical function optimization: artificial bee colony (ABC) algorithm. J Glob Opt. 39 (2007), 459-471.

[16] Holland JH. Genetic algorithms. Sci Am. 267 (1992), 66-72.

[17] Saha N, Panda S. Cosine adapted modified whale optimization algorithm for control of switched reluctance motor, Computational Intelligence, 2020, doi.org/10.1111/coin.12310

[18] Sahu, R.K., Panda, S. and Sekhar, G.C., 2015. "A novel hybrid PSO-PS optimized fuzzy PI controller for AGC in multi area interconnected power systems.” International Journal of Electrical Power and Energy Systems 64: 880- 893

[19] Prangya Mohanty, Rabindra Kumar Sahu \& Sidhartha Panda, A novel hybrid many optimizing liaisons gravitational search algorithm approach for AGC of power systems, Automatika, vol. 61, issue-1, pp.158-178, 2020

[20] Mirjalili S, Hashim SZM. A new hybrid PSOGSA algorithm for function optimization. In: Computer and information application (ICCIA). IEEE. 2010; 374-377.

[21] Eskandar H, Sadollah A, Bahreininejad A, Hamdi M. Watercycle algorithm-a novel metaheuristic optimization method for solving constrained engineering optimization problems. Comput Struct. 110 (2012), 151-166.

[22] Mirjalili S. Moth-flame optimization algorithm: a novel nature inspired heuristic paradigm. Knowl Based Sys. 89 (2015), 228-249.

[23] Mirjalili S. Dragonfly algorithm: a new meta-heuristic optimization technique for solving single-objective, discrete and multi-objective problems. Neural Comput Appl. 27 (2016), 1053-1073.

[24] Pan I, Das S.Fractional order AGC for distributed energy resources using robust optimization. IEEE Trans on smart grid, 7 (2011) 2175-2186.

[25] Padhy S, Panda S, Mahapatra S. A modified GWO technique-based cascade PI-PD controller for AGC of power systems in presence of plug-in electric vehicles, Engineering Science and Technology, an International Journal. 20 (2017) 427-442.

[26] Rajesh KS, Dash SS. Load frequency control of autonomous power system using adaptive fuzzy based PID controller optimized on improved sine cosine algorithm, Journal of Ambient Intelligence and Humanized Computing, 10 (2019), 2361-2373.

[27] Khamari, D, Sahu RK, Panda S. A modified moth swarm algorithm-based hybrid fuzzy PD-PI controller for frequency regulation of distributed power generation system with electric vehicle. J Control Autom Electr Syst (2020). https://doi.org/10.1007/s40313-02000565-0

[28] Debidasi Mohanty, Sidhartha Panda, Robust frequency control of hybrid power system with EV and HP, International Conference on Energy, Power and Environment: Towards Clean Energy Technologies, pp.1-5. IEEE,2021. 


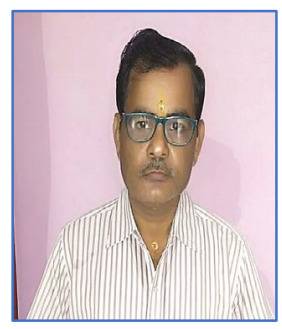

Pabitra Mohan Dash Graduated in Electrical Engineering in 1993, M.Tech Degree in Electrical Engineering in 2008 and Presently he is working as Associate Professor in Electrical Engineering, Bhubaneswar Engineering College, Bhubaneswar, Odisha and Research scholar under BPUT, Odisha. His research interests are the field of Electrical power system and control, Optimization techniques, Flexible AC transmission Controller and Load frequency control.

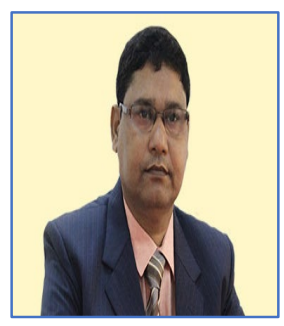

Sangram Keshori Mohapatra received BE degree in Electrical Engineering in the year 1999, M.Tech degree in the year of 2008 in the specialization of Power Electronics and Drives and Ph.D degree in the year of 2014 in the specialization of power system Engineering. He has acquired more than 22 years of experience in the field of Academics and Research pertaining to Electrical Engineering. Presently, he is working as an Associate Professor in Electrical Engineering, Government College of Engineering, Keonjhar a constituent college of BPUT, Odisha. He has published about 60 papers in international journal and conferences. He has guided $25 \mathrm{M}$.Tech research scholars .He is currently guiding 4 Ph.D Research scholars. He is the Life member of Indian Society for Technical Education (ISTE), India and Fellow of The Intuitions of Engineers (IEI) and member of IEEE and reviewer of various repute journal. His research interest is in the area of flexible AC transmission systems (FACTS), modeling of machines, power electronics, power systems and FACTS, controller design, power system stability, optimization Techniques. and Automatic generation and control.

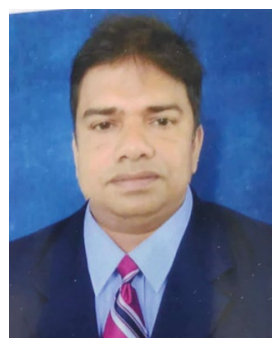

Asini Kumar Baliarsingh received B.E degree in Electrical Engineering from Utkal University in 1998,M.Tech degree in 2004 from NIT, Jamesdpur, India, He received the Ph.D degree in the year 2012.He is currently working in Electrical Engineering Department in Government College of Engineering, Kalahandi, Odisha, India, He has published more than 40 paper in International Journal and Conferences. He has more than 22-year experience in teaching and research experience in the field of Electrical Engineering. He is member of ISTE, India. His research interest are in FACTS Controller, AI techniques, power system stability problem etc. 